\title{
Allo-suckling occurrence and its effect on lactation and nursing duration in harbour seals (Phoca vitulina) in Orkney, Scotland
}

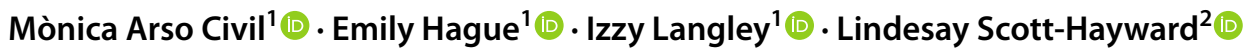

Received: 23 November 2020 / Revised: 28 June 2021 / Accepted: 1 July 2021 / Published online: 17 August 2021

(c) The Author(s) 2021

\begin{abstract}
Fostering and allo-suckling are widespread among pinnipeds, and several hypotheses have been formulated to explain their occurrence. Here, we describe the occurrence of allo-suckling in harbour seals from photo-identification data of females and pups in Orkney (Scotland) during the pupping seasons between 2016 and 2019. We used a generalised linear model framework to investigate the effect of allo-suckling on the duration of lactation (females) and of nursing period (pups). A generalised additive model framework was used to explore how the probability of allo-suckling varied throughout the pupping season, and with changes in mother-pup separation time. Allo-suckling was observed in 31 females, at higher rates (18-37\% of lactating females and $18-47 \%$ of the pups every year) than those observed in other phocid populations, with 13 females allo-suckling in multiple years. The duration of the pups' nursing period was not affected by allo-suckling occurrence. However, females in mother-pup pairs where both mother and pup allo-suckled had longer lactation duration than when only the pup allo-suckled, or than in pairs where no allo-suckling was observed. The probability of allo-suckling increased during the pupping season and with increased mother-pup separation time. However, the proximate causes and the consequences on future reproductive output and pup survival remain unknown.
\end{abstract}

\section{Significance statement}

Allo-suckling, where females nurse others' young, is widespread in pinnipeds, particularly among true seals. Given the high costs of lactation in pinnipeds, allo-suckling is a puzzling behaviour. Using photo-identification and field observations, we examined the occurrence of allo-suckling in harbour seals at a colony in Orkney, Scotland. We found that allo-suckling is common among seals at the study site, and at rates higher than reported elsewhere. Our results show that allo-suckling does not appear to affect the duration of the pups' nursing period but does increase the lactation duration of females who suckle other pups and whose own pups also allo-suckle. This study highlights an area which requires further investigation as the energetic costs and benefits of allo-suckling remain poorly understood.

Keywords Allo-suckling $\cdot$ Lactation duration $\cdot$ Nursing period $\cdot$ Phocids $\cdot$ Harbour seal $\cdot$ Non-filial

\section{Introduction}

Communicated by J. Mann.

Mònica Arso Civil

mac64@st-andrews.ac.uk

1 Sea Mammal Research Unit, Scottish Oceans Institute, University of St Andrews, St Andrews KY16 8LB, UK

2 Centre for Research into Ecological and Environmental Modelling, University of St Andrews,

St Andrews KY16 9LZ, UK
Lactation incurs elevated energetic costs in mammals (Lee 1996). It can therefore impose physiological stress on females which then may consequently reduce their survival and future reproductive success (Clutton-Brock et al. 1989; Desprez et al. 2018). In pinnipeds, females have to balance the energy expenditure of lactation on land with the energy intake of foraging at sea (Bowen et al. 2009). This has led to the evolution of three lactation strategies. Otariids (i.e. sea lions and fur seals) are classified as income breeders, characterised by low milk fat content (19-50\%; Oftedal et al. 1987) which is compensated for by a foraging-cycle strategy 
(Bowen 1991). Females forage over an extended lactation period (4-18 months; Schulz and Bowen 2004), frequently separating from their pups for long periods of time. Walruses also have an extended lactation, which can last between two and three years, and pups accompany the females on foraging trips and can suckle at sea (Bowen et al. 2009). Female phocids (i.e. true seals) are classified as capital breeders, characterised by a high milk fat content $(40-60 \%$; Boness et al. 1994) and a fasting strategy where females use large body energy stores (i.e. blubber) accumulated prior to parturition to sustain themselves and to suckle their pups during a comparatively short lactation period (4 to 60 days; Bowen et al. 2009), finishing with the abrupt weaning of the pup (Bowen 1991).

Harbour seals (Phoca vitulina) differ slightly from this classic phocid capital breeding lactation strategy. Females will forage over a large proportion of the, on average, 24-day lactation period (Boness et al. 1994; Thompson et al. 1994), to support the energetic demands of nursing and of their own metabolism (Bowen et al. 1992, 2001). Milk composition is high in fat content (40-50\%), although not as high as in other phocid species such as grey seals (Iverson et al. 1993; Lang et al. 2005). As in other phocid species, harbour seal milk composition changes over lactation, with milk fat content rapidly increasing during the first week post-partum from 41 to $50 \%$ and then remaining relatively constant throughout the remaining lactation, although there is considerable individual variation both in milk composition and in the changes in milk fat content (Oftedal et al. 1987; Iverson et al. 1993; Lang et al. 2005). Females seem to feed little in the early lactation, when pups are days old, but will resume foraging trips mid to late lactation before the pups are weaned (Boness et al. 1994; Thompson et al. 1994; Bowen et al. 1999). Harbour seal pups can swim from birth and will sometimes accompany their mothers during these foraging trips but often stay unattended on land. Females will come back to the haulout site between foraging bouts to nurse their pups (e.g. Sable Island; Bowen et al. 1999). Harbour seal mother-pup pairs spend a large proportion of the time in the water, and often switch between haulout sites with the tidal cycle; pups sometimes move between nearby locations while separated from the mother (Boness et al. 1992; Thompson et al. 1994). Consequently, available information on harbour seal mother-pup pair separation time is limited and only available from a few studies where both females and pups have been equipped with telemetry devices to track their locations. These studies indicate females seem to spend significantly more time at sea than pups prior to weaning (Boness et al. 1994; Bowen et al. 1999; Reder et al. 2003).

Weaning can be determined from changes in blood plasma opacity levels, which are an indication of recent suckling, and from changes in pup's body mass, both requiring the repeated capture and sampling of pups during lactation (Muelbert and Bowen 1993; Cottrell et al. 2002). In studies where captures are not possible, weaning can be established from observations of pups without their mothers (Bowen 1991). However, observers need to account for the fact that mothers can temporarily separate from their pups during lactation (e.g. to forage) and both mothers and pups will be out of sight when in the water (Bekkby and Bjørge 2003; Cordes and Thompson 2013).

Fostering (caring for another's young) and allo-suckling (nursing another's young) have been documented in multiple mammal and bird species (see Riedman (1982) for a review). In pinnipeds, females may be seen nursing nonfilial (unrelated) pups once separated from their own pups or may simultaneously nurse their own and other pups. Several hypotheses have been suggested to explain fostering and allo-suckling behaviour in seals. These include lack of maternal experience (Lunn 1992), females being unable to recognise their own pups (Bowen 1991; Insley et al. 2003), mother-pup temporary separation or loss of own pup (e.g. Boness et al. 1992), and kin selection, although studies have shown no support for preferential allo-suckling of pups born to female relatives (Perry et al. 1998; Schaeff et al. 1999; Hoffman and Amos 2005). Allo-suckling seems to be more common among phocids than in otariids (Boness et al. 1992). For example, fostering and milk stealing (which involves a female sleeping or apparently unaware of the presence of a non-filial pup suckling) are very common in the Mediterranean and Hawaiian monk seals (Boness et al. 1998; Aguilar et al. 2007), and are also observed in grey seals (Perry et al. 1998; McCulloch et al. 1999), northern elephant seals (Riedman and Le Boeuf 1982) and harbour seals (Boness et al. 1992; Schaeff et al. 1999). However, the proximate causes for the evolution of allo-nursing behaviours are generally poorly understood (Packer et al. 1992; Roulin 2002), and the variability in frequency across taxonomic groups could reflect variation in costs (Boness 1990; MacLeod and Lukas 2014).

In Scotland, numbers of harbour seals have shown contrasting population trajectories between different regions over the last two decades (Thompson et al. 2019). To help understand the potential drivers behind these regional trends, a long-term photo-identification (photo-ID) study was initiated in 2016 to estimate survival and fecundity rates of harbour seals in areas of contrasting population trajectories (Arso Civil et al. 2016). Harbour seals can be individually identified from their pelage markings (e.g. Hastings et al. 2008; Cunningham 2009). These markings are present from birth, as newborn harbour seals shed their lanugo (white coat) in the womb (Burns 2009). Mother-pup pairs may therefore be monitored using photo-ID. During photo-ID data collection at haulout sites in Orkney, a number of identified females were observed allo-suckling non-filial pups.

Here, we describe the occurrence of allo-suckling behaviour in harbour seals across four pupping seasons at haulout sites in Orkney. We first investigated whether the number of 
days a female or a pup was seen nursing was different when allo-suckling occurred. We hypothesised that if allo-suckling is costly to females, a female would extend her lactation period to compensate her own pup or would only allow allo-suckling after weaning her own pup. Conversely, if allo-suckling is beneficial to pups, we predicted they would extend their nursing period by allo-suckling from females other than the mother. We then modelled the probability of allo-suckling (versus suckling a filial pup) to understand if allo-suckling occurrence changed throughout the pupping season and to explore whether it was influenced by an increase in separation time between mothers and pups.

\section{Methods}

\section{Field methods and identification of mother-pup pairs}

Photo-ID data and associated observations of harbour seals were collected during the breeding seasons (June and July) of 2016 to 2019, inclusive, at three neighbouring haulout sites in Burray ( $\left.58^{\circ} 50^{\prime} 55^{\prime \prime} \mathrm{N}, 002^{\circ} 57^{\prime} 47^{\prime \prime} \mathrm{W}\right)$ and Widewall Bay (58 48' 33" N, $\left.002^{\circ} 59^{\prime} 05^{\prime \prime} \mathrm{W}\right)$, Orkney (Fig. 1). From the start of each field season, data were collected at each site at least once every 3 days. Following the sighting of the first pup, data were then collected daily or every 2 days at each site, subject to the weather. Surveys started approx. $1 \mathrm{~h}$ before low tide and lasted between 2 and $4 \mathrm{~h}$ until all hauled out seals (including pups) had been photographed. It was not possible to record data blind because our study involved focal animals in the field.

Photographs of the head and neck area of each seal present at the haulout site were taken from 40 to $150 \mathrm{~m}$ away (depending on the site), using a digital camera (Canon EOS 70D SLR) attached to a scope (Swarovski ATS 80 with $\times 20-60$ eyepiece and TLS-APO 30mm). Photographs were first graded for photographic quality following a protocol modified from Cunningham (2009) and the best quality photographs (seal head is perpendicular to the camera, in focus, with good contrast/brightness) were used to match each individual to a catalogue of known seals using computer-assisted pattern matching software (Wild-ID; Bolger et al. 2012) and manual matching. Pups were also identified based on the unique pattern of their pelage in the head and neck area as well as in the flanks.

Given the wider project's objectives (see Arso Civil et al. 2016), the priority was to photo-identify all individuals (not only mother-pup pairs) present at the haulout site in each survey. This meant it was not possible to implement an experimental design to monitor suckling patterns and behavioural interactions between targeted lactating females and pups (e.g. Boness 1990; Smiseth and Lorentsen 2001; Aguilar et al. 2007). Instead, efforts were made to identify
Fig. 1 Location of the three nearby haulout sites where the study was conducted in Orkney, Scotland

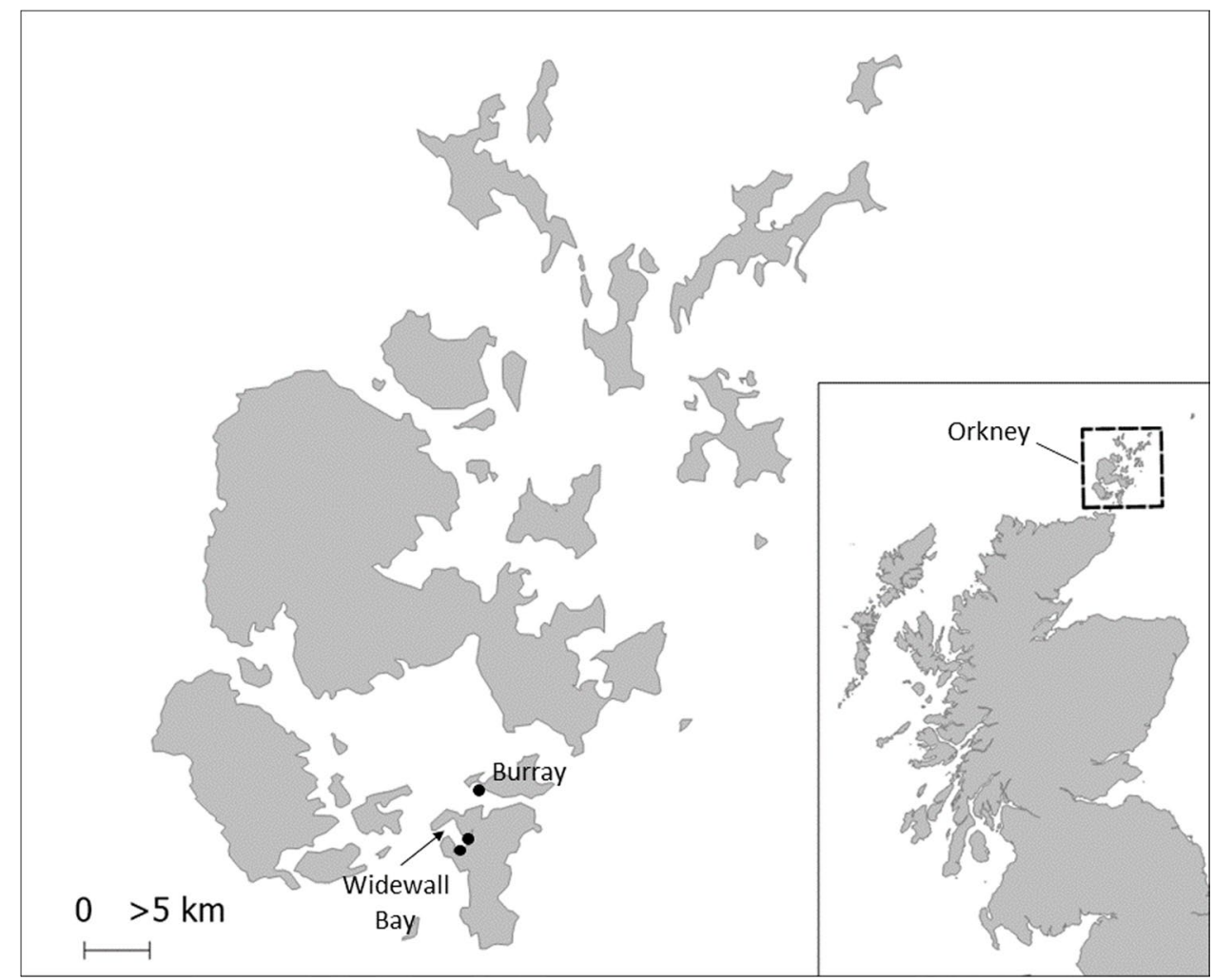


both the female and the pup in each photographic encounter, photograph suckling events and characterise interactions between breeding females and pups (see below).

Frequently, females could be identified as pregnant from photographs and field observations based on the major change in body shape during late gestation, indicating an imminent birth. Direct observation of births occurred but was rare, and most pups were assumed to be first observed within the first few days after being born, based on pup size, the presence of an umbilicus and/or the day-to-day observations of females. Mother-pup pairs (filial) were identified based on repeated observations of a female with a newborn or a very young pup.

\section{Allo-suckling behaviour and lactation duration}

Behavioural interactions between identified breeding females and non-filial pups were characterised based on field observations and photographic evidence. Allo-suckling was defined as a female allowing a non-filial pup to suckle, in the presence or absence of her own pup, or a pup suckling from a female other than its mother. Milk stealing, which involves the female sleeping or apparently unaware of the presence of a non-filial pup suckling (Aguilar et al. 2007; Maniscalco et al. 2007) was never observed during this study. Identified mother-pup pairs were classified into four groups based on the occurrence of allo-suckling within each pair, as defined in Table 1.

Following Cordes and Thompson (2013), pupping date was calculated as the midpoint between the last day a female was seen alone and the first day she was seen with her pup when that period was less than or equal to 3 days. If that period was $>3$ days, pupping date could not be calculated accurately and was excluded from the analysis. Lactation duration and nursing period were calculated for females and for pups, respectively, as the number of days between an accurate pupping date (converted to Julian day, i.e. day of the year) and the last day a mother-pup pair were seen together, or, to the last day a female (for lactation duration) or a pup (for nursing period) were seen allo-suckling, whichever was latest. This was done to reflect that females' lactation duration and pups' nursing period could be effectively extended if a female allo-suckled a non-filial pup after having weaned

Table 1 Mother-pup pair groups based on the occurrence of allosuckling within each pair

\begin{tabular}{ll}
\hline Group & Definition \\
\hline MP & Neither the female nor the pup is observed allo-suckling \\
P_allo & Only the pup is ever observed allo-suckling \\
M_allo & Only the female is ever observed allo-suckling \\
Both_allo & Both the female and the pup are observed allo-suckling
\end{tabular}

its own pup or a pup allo-suckled after being weaned from its mother. In order to ensure the end of lactation (females) or nursing (pups) was a reflection of weaning and not just of a foraging trip or a short separation between mother and pup, lactation duration and nursing period were only calculated if the female or the pup were seen on their own, within 10 days of the last mother-pup pair sighting (Cordes and Thompson 2013). Mother-pup pairs only seen once $(n=4)$ and a female first seen with a dead pup $(n=1)$ were excluded from the analysis.

\section{Modelling lactation duration and nursing period}

A generalised linear model (GLM) with a quasi-Poisson error distribution to account for over-dispersion in the data was fitted, with lactation duration for mothers as the response variable and year, pupping date (centred on the annual median, i.e. relative pupping date) and allo-suckling group (see Table 1) as the explanatory variables within the model. There was no evidence that a more flexible relationship between pupping date and lactation duration was required. A GLM with an interaction term between relative pupping date and allo-suckling group was also included to investigate whether variation in lactation duration between allo-suckling groups was dependant on when a female pupped within the summer. Model selection was based on the Quasi Akaike Information Criteria (QAIC $)$ ) (Burnham and Anderson 2002) using the package "MuMIn" (Barton 2019) in R (R Core Team 2019). The same set of models and error structure were fitted to the pup data, to model the nursing period in pups as a function of the same explanatory covariates as for the mothers, with model selection done as above. To interpret differences in the predicted lactation duration or nursing period by allo-suckling group or with relative pupping date, confidence intervals around model coefficients from the most supported model(s) were obtained and transformed to the response scale.

Repeated measures from individuals in different years (in this case lactation duration of females) may result in a positive residual correlation that can lead to underestimation of the uncertainty of model parameters if not considered (e.g. Bowen et al. 2006; Cordes and Thompson 2013). It was unlikely in this instance as only 8 of the 38 females were observed for 3 or more of the years, and it is difficult to get a good approximation of correlation with so few observations. Nevertheless, an autocorrelation function (ACF) plot ("acf" function in the "stats" package in R) was used to visualise the residuals of a model with pupping date and allo-suckling group as explanatory variables (with the data ordered by female ID). Additionally, using female ID as a panel structure, robust standard errors were estimated for the same model (using the MRSea package; Scott-Hayward et al. 2018). Based on a comparison of the robust and raw 
standard errors along with the ACF plot, there was no evidence for positive residual correlation. Thus, we assumed all annual observations of a female were independent for modelling purposes.

\section{Modelling allo-suckling occurrence}

All observed suckling (female-filial pup pair) and allo-suckling (female with non-filial pup) events in which both the female and the pup could be identified were collated over the four-year study period. Multiple observations of suckling or allo-suckling by the same female and pup pair within the same day were summarised into single daily events to avoid duplicates and limit observer bias. The probability of allo-suckling was modelled within a Bernoulli generalised additive model (GAM) framework, to allow for non-linear relationships between the covariates and the response; allosuckling occurrence. The response had two possible outcomes: 0 for a mother-pup pair suckling event; 1 for an allosuckling event. The variables available were Julian day, year, pupping date, days since birth (for the female and for the pup in the observation, when available), and days since the mother-pup pair was last photographed together (dsMP_M $=$ days since the female in the observation was last photographed with her pup, and dsMP_P = days since the pup in the observation was last photographed with its mother). Pupping date and days since birth were not recorded for all mother-pup pairs, so to assess their usefulness as predictors, models were evaluated on the reduced data set, for which records were available. Using AIC for model selection, neither variable was selected for, so the modelling proceeded with the full set of mother-pup pairs. Despite not being able to include birth-related covariates (i.e. pupping date and days since birth), Julian day could be used as a proxy for days since birth for the female or the pup (Pearsons correlation coefficient $=0.85$ (female) and 0.83 (pup)).

The continuous variables were permitted to have a smooth or a linear relationship with the response. Smooth terms were fitted as quadratic (degree 2) $B$-splines and the flexibility restricted to a maximum of 5 degrees of freedom. The exact number and location of the knots was determined using a Spatially Adaptive Local Smoothing Algorithm (Walker et al. 2011) and 10-fold cross validation. Residual correlation, most likely driven by female ID (based on the ACF plots) was permitted by including a panel variable for female ID and calculating robust standard errors. The "MRSea" package was used for model fitting.

Model selection was achieved by using an AIC-based forward selection procedure. Each variable was added one at a time until the AIC no longer improved (i.e. $\Delta$ AIC $<2$ compared to the competing model). The order of variables was determined using the AIC scores of single variable models. At each step, collinearity between variables was checked using generalised variance inflation factors (GVIF). These were calculated using the "vif" function in package "car" in $\mathrm{R}$ (Fox and Weisberg 2019). If collinearity was detected, the variable was not considered for inclusion.

Predictions of the probability of allo-suckling were generated from the most supported model, based on AIC score, and used to assess the estimated relationships between allosuckling occurrence and the retained variables. Uncertainty around the predictions was estimated using a parametric bootstrap on the model coefficients and the robust covariance matrix (i.e. variances adjusted for correlation). 95\% confidence intervals were calculated using the lower 2.5 and upper 97.5 quantiles of the bootstrapped predictions (from 1000 bootstraps). Additional statistics available within the "MRSea" package were used to assess the influence, if any, of each female (panel variable in the models) on the precision of the parameter estimates (COVRATIO statistic) and on the sensitivity of model predictions (predicted residual sum of squares; PRESS statistic). COVRATIO values < 1 signal that removing those females will decrease model standard errors, and COVRATIO values $>1$ signal that removing those females will inflate model standard errors (Belsley et al. 1980). Relatively large PRESS values signal model predictions are sensitive to removing those particular females (panels) (Allen 1971).

\section{Results Mother-pup pairs and observed allo-suckling}

Between 2016 and 2019, 64 females gave birth at least once, although the number of mother-pup pairs declined each year, from 43 pairs in 2016, to 41 in 2017, 34 in 2018 and 29 in 2019. A total of 77 accurate pupping dates were obtained over the four breeding seasons from 42 females. Pupping dates ranged from 8 June to 4 July, with $90 \%$ of pups being born within the first 9 to 16 days (after the first observed pup) each year. Of the mother-pup pairs with accurate pupping dates $(\mathrm{n}=77)$, weaning date could be estimated in 66 cases (16 in 2016, 19 in 2017, 17 in 2018 and 14 in 2019) to allow calculation of lactation duration in females and of nursing period in pups, in the different allo-suckling occurrence groups (Table 2).

For females, observed lactation duration ranged between 1 and 32 days, with an overall mean of $19.6 \pm 8.4$ days (mean \pm standard deviation). For pups, observed nursing periods ranged between 0 and 32 days, with a mean of 18.9 \pm 8.0 days. These observed periods varied depending on the occurrence of allo-suckling within the pair (Table 2). On two occasions where nursing period length was 0 to 1 day, the pups were abandoned and assumed dead (although one of the pups was seen allo-suckling for a further 4 days). On another two occasions where lactation duration was 3 days, the pups were not seen afterwards associated to the mothers and thus were assumed dead or fostered by a different, 
Table 2 Observed lactation duration (days \pm standard deviation) for females and nursing period (days \pm standard deviation) for pups depending on the occurrence of allosuckling within a mother-pup pair, as defined in Table 1. Sample size (n) indicates the number of females or pups in each group

\begin{tabular}{lllll}
\hline Females/pups & Allo-suckling group & $\mathrm{n}$ & $\begin{array}{l}\text { Mean lactation duration/nursing } \\
\text { period (days) } \pm \text { SD }\end{array}$ & Range (days) \\
\hline Females & MP & 30 & $18.7 \pm 8.0$ & 3 to 32 \\
& Both_allo & 10 & $25.8 \pm 4.5$ & 18 to 32 \\
& M_allo & 13 & $20.9 \pm 7.5$ & 10 to 32 \\
& P_allo & 13 & $15.6 \pm 9.9$ & 1 to 31 \\
Pups & Overall & 66 & $19.6 \pm 8.4$ & 1 to 32 \\
& MP & 30 & $18.7 \pm 8.0$ & 3 to 32 \\
& Both_allo & 10 & $22.9 \pm 7.2$ & 7 to 32 \\
& M_allo & 13 & $14.5 \pm 8.0$ & 0 to 30 \\
& P_allo & 13 & $20.6 \pm 7.2$ & 5 to 31 \\
& Overall & 66 & $18.9 \pm 8.0$ & 0 to 32 \\
\hline
\end{tabular}

but unidentified female(s). However, some short female lactation periods (e.g. 5 to 8 days) resulted in their pups extending their nursing periods up to 17 to 23 days due to allo-suckling.

Over the study period, 31 different females were observed allo-suckling at least in 1 year, with some females observed allo-suckling in $2(n=9)$ or $3(n=4)$ separate years. Every year, $18-37 \%$ of the females pupping were observed allosuckling non-filial pups (range 8 to 15 females per year, each female allo-suckling 1 to 5 different pups in a single year). These females were seen allo-suckling on 1 to 6 occasions each year $($ mean $=1.68, \mathrm{SD}=1.32$ ). From the pups' perspective, allo-suckling observations involved $18-47 \%$ of the identified pups every year (range 8-16 pups per year, each pup allo-suckling from 1 to 3 different females)

There were 293 observations involving suckling in which both the female and the pup could be identified ( 57 females and 116 pups $)$ of which $74(25.2 \%$, mean $=18.5$ observations per year, $\mathrm{SD}=7.4$ ) were allo-suckling events. There were another 11 allo-suckling observations in which the pup did not match the female's known pup nor could the pup be assigned to any other female; these data were excluded from the analysis (1 in 2016, 2 in 2017, and 8 in 2018; all photographed pups in 2019 were identified). On 33 occasions, the mother of the non-filial pup allo-suckling was photographed at the haulout site during the observational period conducted on that same day, on 8 occasions, the filial pup of the allosuckling female was photographed on the same day, and on 6 occasions, both the non-filial pup's mother and the allosuckling female's pup were photographed on the same day.

Allo-suckling was observed throughout most of the pupping season, as early as June 18 (Julian day 169, 1 day before the overall annual median pupping date) and as late as July 22 (Julian day 203, 33 days after the overall annual median pupping date) (Fig. 2a). Most allo-suckling events were observed 14 to 24 days after the female gave birth, compared to (filial) suckling events, which were mostly observed 3 to 17 days after birth (Fig. 2b). Figure 3 shows when these events were observed for mother-pup pairs for which an accurate pupping date was available. A high proportion of these allo-suckling events occurred beyond the mother-pup association time, $51 \%$ for females $(n=24$; dark blue dots in "M_allo" and "Both_allo" in Fig. 3) and 63.4\% for pups $(n=26$; light blue dots in groups "P_allo" and "Both_allo" in Fig. 3).

On four occasions (two in 2017 and two in 2018), the pups observed allo-suckling looked underweight from visual inspection of photographs/videos and field observations, where the rib cage and spine were clearly marked under
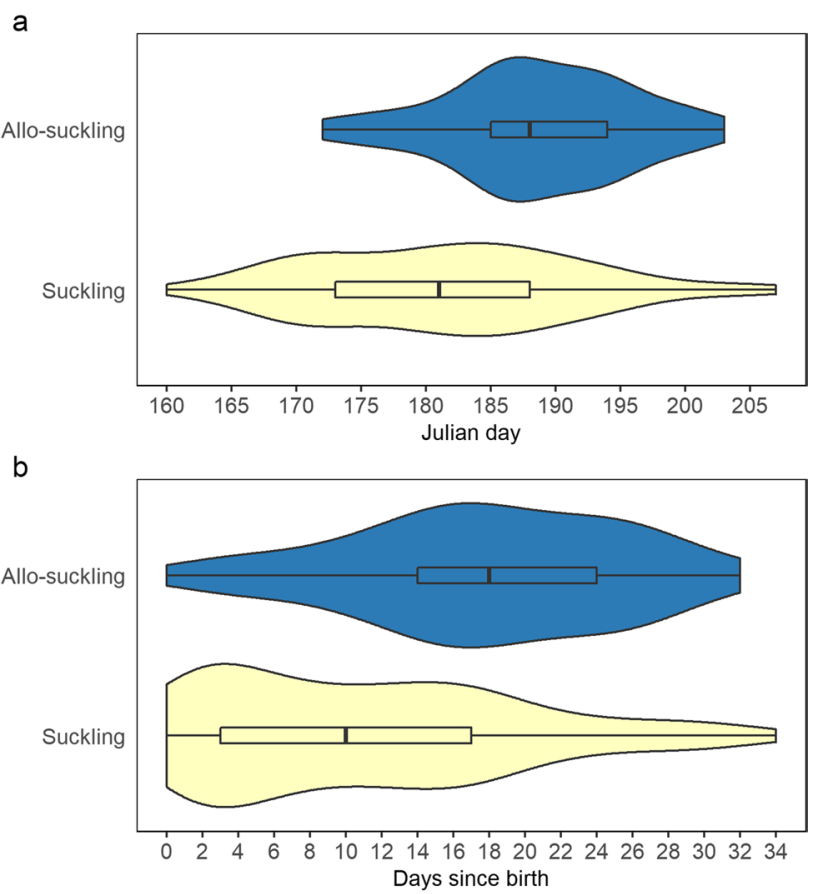

Fig. 2 Observed suckling (female with her own pup, yellow) and allosuckling (female with non-filial pup, blue) events by Julian day (a) and by days since the female gave birth (b) for the combined breeding seasons of 2016 to 2019. Boxplots with the data ranges, and 25th, 50th and 75th percentiles are shown 


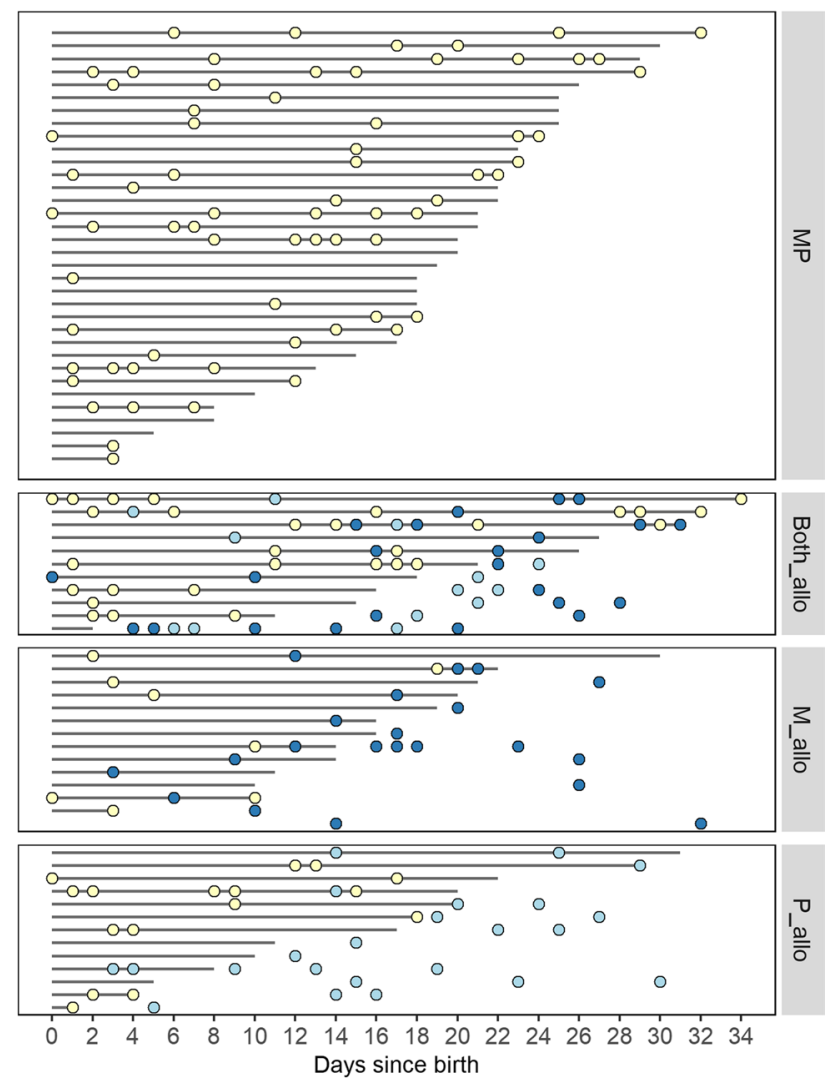

Fig. 3 Observed suckling and allo-suckling events in mother-pup pairs with an accurate pupping date. Classified by allo-suckling group (Table 1), each line represents the length of time (in days) a motherpup pair was seen associated (i.e. seen together in photographs). Dots represent suckling events: yellow dots are suckling events of motherpup pairs and so appear in all four groups. The blue dots are allosuckling events by females (dark blue) and pups (light blue) from the groups "Both_allo" (both mother and pup are observed allo-suckling), "M_allo" (only the mother is ever observed allo-suckling) and "P_allo" (only the pup is ever observed allo-suckling). MP, neither the female nor the pup are observed allo-suckling the skin, indicating a very thin blubber layer. Three of these pups were assumed abandoned as they were only seen in association with their mothers for 2, 3 and 8 days respectively, after being born. The fourth pup was still observed in association with its mother 20 days after birth, despite looking underweight. Fostering (rather than intermittent allo-suckling) was observed once in 2018 when a female fostered a non-filial pup; the female subsequently abandoned her own pup.

\section{Lactation duration and nursing period analysis results}

The most supported model for lactation duration (females) and for nursing period (pups) included relative pupping date as a linear term and allo-suckling group (Table 3). For pups, however, a model without allo-suckling group was equally supported ( $\Delta$ QAIC $_{c} 1.20$, Table 3 ) and so in the interest of parsimony, this second model was chosen as the best nursing period model. Neither annual variation nor the interaction term (relative pupping date $\times$ allo-suckling group) was considered important predictors of lactation duration or of the nursing period.

Results showed that lactation duration was significantly longer for females pupping early in the season compared to those pupping later regardless of the allo-suckling group (relative pupping date, $\mathrm{t}=-3.312, \mathrm{p}=0.001$ ). The model indicates that we are $95 \%$ sure the true value of females' lactation duration was between 0.94 and 0.98 times shorter for every 1-day increase in relative pupping date. Some significant differences in estimated lactation duration between allo-suckling groups were also identified. Based on the estimated model coefficients (on the response scale), lactation duration for females in the group where both mother and pup allo-suckled (Both_allo, baseline group) was estimated to be between 1.3 and 2.4 times longer than for females whose pups allo-suckled but they did not $(\mathrm{P}$ _allo, $\mathrm{t}=-3.401, \mathrm{p}$ $=0.001)$. Estimated lactation duration for females in pairs
Table 3 Table of models fitted to investigate variation in lactation duration in females (top half) and of the nursing period in pups (bottom half) by allo-suckling group and year between 2016 and 2019. Var number of estimated variables; $\triangle Q A I C c$, difference in QAICc compared to most supported (top) model; relative $D O B$, relative pupping date. Models chosen for inference are in bold

\begin{tabular}{llcc}
\hline Dataset & Model & Var & $\Delta$ QAIC $_{\mathrm{c}}$ \\
\hline Female lactation duration & Relative DOB + allo-suckling group & 6 & 0.00 \\
& Relative DOB & 3 & 4.61 \\
& Relative DOB $\times$ allo-suckling group & 9 & 5.23 \\
& Relative DOB + allo-suckling group + year & 9 & 6.60 \\
& Allo-suckling group & 5 & 8.35 \\
& Year & 1 & 16.47 \\
Pup nursing period & Relative DOB + allo-suckling group & 6 & 0.00 \\
& Relative DOB & 3 & 1.20 \\
& Relative DOB $\times$ allo-suckling group & 9 & 6.45 \\
& Allo-suckling group & 5 & 5.54 \\
& Relative DOB + allo-suckling group + year & 9 & 7.62 \\
& Year & 5 & 12.01 \\
\hline
\end{tabular}


where both females and pups engaged in allo-suckling (Both_allo) was also between 1.1 to 1.8 times longer than for females in the mother-pup suckling-only group (MP, $\mathrm{t}$ $=-2.409, \mathrm{p}=0.019$ ), but was not significantly different to those in the group where only mothers allo-suckled (M_allo, $\mathrm{t}=-1.582, \mathrm{p}=0.119$ ).

Similar to lactation duration of females, the nursing period was also found to be significantly longer for those pups born earlier in the season compared to later $(\mathrm{t}=-2.726$, $\mathrm{p}=0.008$ ). Specifically, for every 1-day increase in relative pupping date, the nursing period was estimated to be between 0.95 and 0.99 times shorter for pups (Fig. 4).

\section{Allo-suckling occurrence analysis results}

The most supported model for allo-suckling probability included Julian day, dsMP_M (days since female in the pair was seen with her pup) and dsMP_P (days since the pup in the pair was seen with its mother) as linear terms and year as a factor variable. Smooth terms were trialled but unsupported by the data (they resulted in overfitted and biologically illogical models). Robust standard errors were used for inference as there was evidence of minor residual correlation (lag 1 correlation $=0.15$ ). The population average probability of allo-suckling increased with Julian day (Fig. 5) and with increasing separation time between mothers and pups (Fig. 6).

There were 2 females with COVRATIO statistics of approximately 0.8 , which if removed would reduce the variance in the model. One of these females never allo-suckled and the other, on two occasions, allo-suckled the same day as suckling her own pup. There were three females that strongly influenced the predictions by increasing the probability of allo-suckling (based on PRESS statistics values). Unsurprisingly, two of these were the females with the most data (18 and 15 suckling/allo-suckling events each). The third female was only seen suckling her own pup once and allo-suckling on another 7 occasions. While interesting, none of these findings, regarding the influence of particular females on the precision of the parameter estimates and on the sensitivity of model predictions, was extreme enough to warrant changes to the data.
Fig. 4 Estimated relationship between lactation duration (days) for mothers (a) and nursing period (days) for pups (b), and relative date of birth and allo-suckling group, using the highlighted models in Table 3. The shaded areas are the $95 \%$ confidence intervals around predicted lactation durations and nursing period, and the dots are the observed lactation or nursing period durations

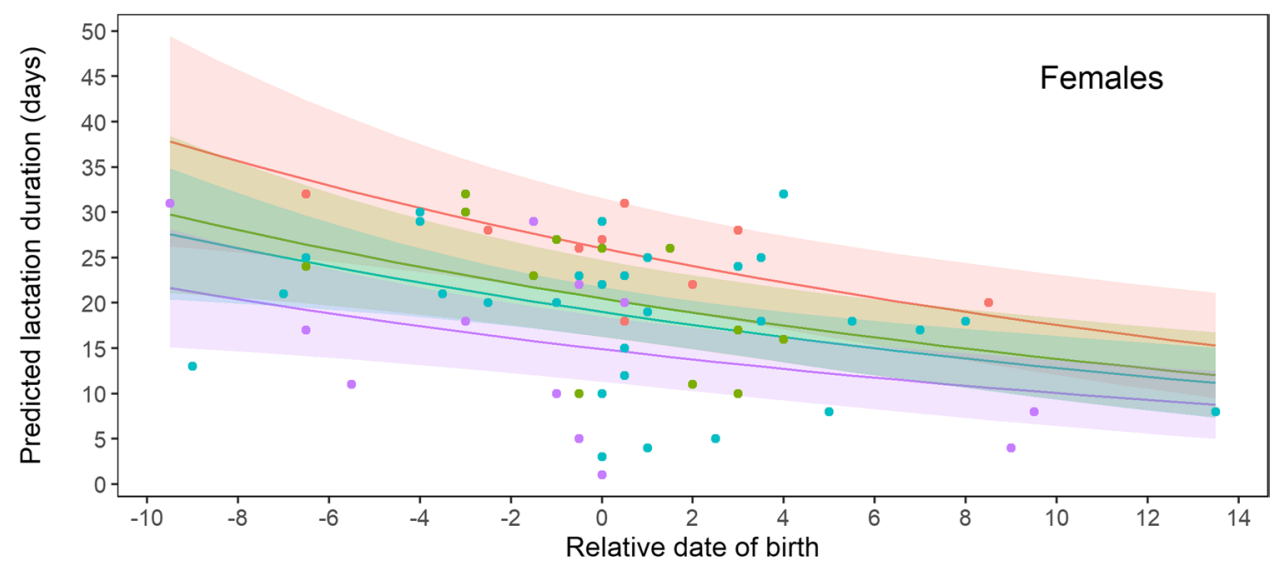

b

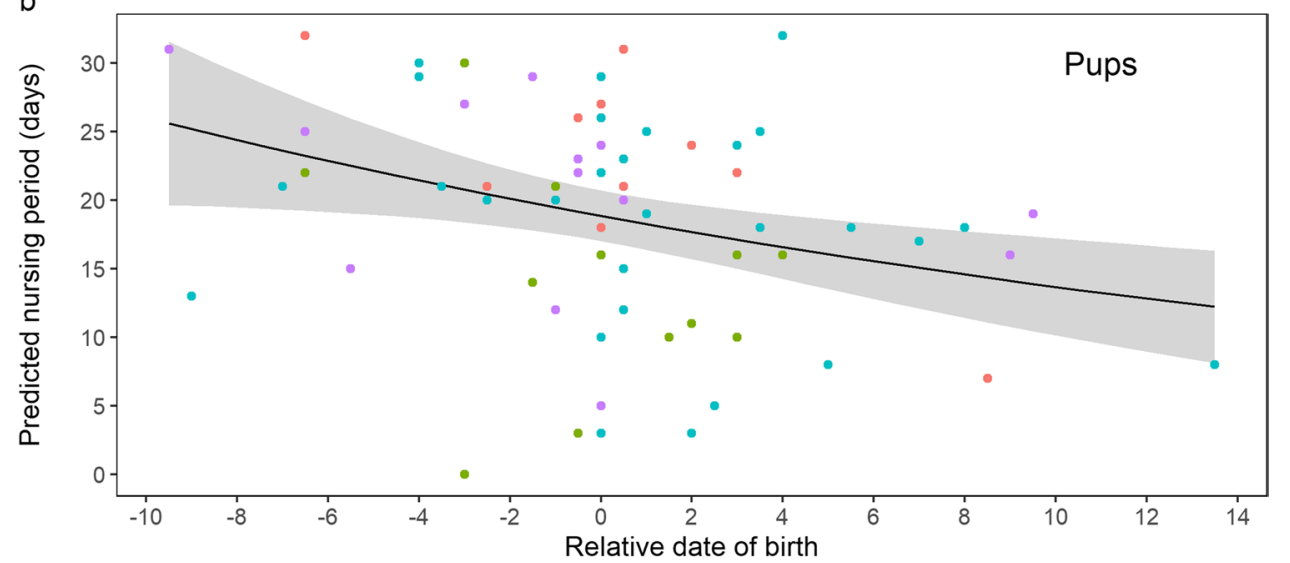


Fig. 5 Predicted probability of allo-suckling for 2016 to 2019 , using median dsMP_M (days since female in the pair was seen with her pup) (median $=$ 2 days) and median dsMP_P (days since pup in the pair was seen with its mother) (median $=2$ days). The shaded areas are the predicted $95 \%$ confidence intervals and a rug plot with the actual observations is shown at the bottom and top of each plot

Fig. 6 Predicted probability of allo-suckling with changing values of dsMP_M (days since female in the pair was seen with her pup) for 3 values of dsMP_P (days since pup in the pair was seen with its mother) (top) and with changing values of dsMP_P for 3 values of dsMP_M (bottom). These predictions were generated with median values for year and Julian day (year $=2017$, Julian day $=185$ ). The shaded areas are the predicted $95 \%$ confidence intervals and a rug plot with the actual observations is shown at the bottom and top of each plot
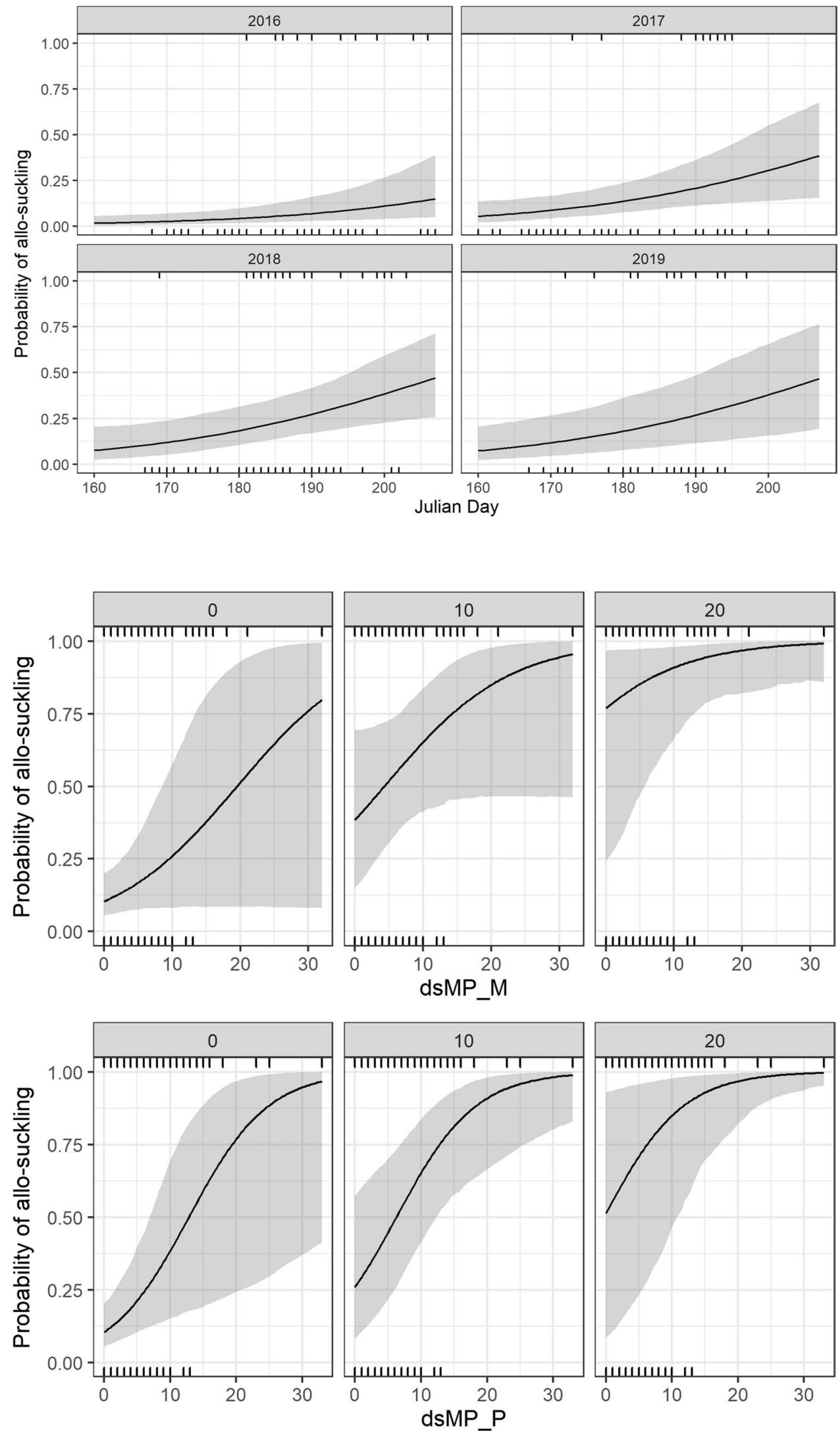


\section{Discussion}

Allo-suckling and fostering behaviour are frequently observed in pinniped species, particularly among phocids, although the proximate causes and the subsequent consequences on reproductive success and survival are not fully understood. This study investigated the occurrence of allo-suckling behaviour and its effect on the duration of lactation (females) and nursing period (pups) at harbour seal haulout sites in Orkney, Scotland.

Allo-suckling was observed in every pupping season, involving $18-37 \%$ ( $n=8$ to 15 ) of the identified breeding females and $18-47 \%$ ( $n=8$ to 16$)$ of the identified pups, each year. Contrary to observations of harbour seal populations at Sable Island (Canada) where females were only seen nursing a non-filial pup once separated from their own (Boness et al. 1992), females in Orkney allo-suckled while caring for their own pup, but also kept allo-suckling once no longer associated with their own pup. The percentages of females and pups allo-suckling reported here are higher than for harbour seals on Sable Island (10\% of females allo-suckled during their lactation, Boness et al. 1992; 4.6 to $14.4 \%$ of females fostered pups, Schaeff et al. 1999), and at breeding colonies of grey seals at Sable Island (2.9 to $28 \%$ of females fostered simultaneously, Perry et al. 1998). They are also higher than for Antarctic fur seals on Bird Island (11.47\% of females, Gemmell 2003; $9.9 \%$ of pups, Hoffman and Amos 2005), or for New Zealand sea lions (6\% of females in a given survey, Childerhouse and Gales 2001), but lower compared to Hawaiian monk seals (53 to $90 \%$ of the females, Boness et al. 1998).

A study conducted by Rubertus (1983) at one of the three haulout sites of the present study during the pupping season of 1982 reported the presence of lone (presumably weaned or orphaned) pups following females and interrupting ongoing suckling events in order to suckle, as well as of a single observation of simultaneous nursing of two pups. These observations suggest allo-suckling behaviour might have been occurring for some time at this particular colony, but it remains unknown whether its prevalence has changed over time or with potential changes in population dynamics given the declining population trajectory in this region (Thompson et al. 2019).

Lack of maternal experience has been suggested as a contributing factor to fostering and allo-suckling in pinniped species, including harbour seals (Boness et al. 1992). It was not possible to distinguish young, inexperienced harbour seal mothers from older females based on their body size in the photo-identification data, because female harbour seals will reach $90 \%$ of their asymptotic length (indicative of sexual maturity ) by the age of 3.2 years (Hall et al. 2019). However, 11 of the breeding females included in this study could be aged from counts of growth layer groups in the incisors (Hall et al. 2019) when captured and sampled as part of a broader research project in 2016 and 2017 (Arso Civil et al. 2018). These included 4 females aged 4 to 14 (mean $=10.1$ ) in years observed suckling their own pups only, and seven females aged 5 to $18.5($ mean $=10.7)$ in years observed allo-suckling other pups. Most of these 11 breeding females were likely to be multiparous as female harbour seals tend to have the first pup at ages 4 to 6 (Boulva and McLaren 1979). Additionally, some other multiparous females of unknown age were also seen allo-suckling in different years. This suggests that lack of maternal experience is unlikely to be driving the observed allo-suckling behaviour in females from this study.

We could not establish whether allo-suckling occurrence was linked to failed mother-pup recognition, a factor that has been correlated with increased allo-suckling occurrence in phocids compared to otariids, given their less developed mother-pup recognition (Insley et al. 2003). The observed behaviours between mothers and pups were in line with other harbour seal studies regarding mother-pup recognition; pups called frequently, especially within the first week after birth, and mostly when in the water with the mother, or when left alone at the haulout site (e.g. Renouf 1984; Sauvé et al. 2015). Mother-pup pairs showed a high degree of noseto-nose contact, both in the water or on land (e.g. Wilson and Jones 2018). Also, lone females arriving to the haulout site could be observed approaching several pups on land to smell them (e.g. Boness et al. 1992; Schaeff et al. 1999), until successfully finding their pup, generally followed by a suckling bout. On some occasions, the pup was found in the company of, or allo-suckling from, another female, which generated an aggressive interaction from the mother towards that female before reuniting with her pup. Some females were also observed reacting aggressively towards approaching non-filial pups when pregnant, during lactation and after weaning their pups.

The timing of allo-suckling in relation to lactation varies between pinniped species and colonies but can be observed as simultaneous nursing of a filial and non-filial pup(s) or as the sequential nursing of pups after separating from one's own pup. In otariids, allo-suckling and fostering behaviours are uncommon, but simultaneous nursing has been observed in different species of sea lions, including New Zealand, Australian, and Steller sea lions (Childerhouse and Gales 2001; Maniscalco et al. 2007; Pitcher et al. 2011). Antarctic fur seals have also been observed allo-suckling pups, either after losing or while nursing their own pup (Lunn 1992; Hoffman and Amos 2005). In phocids, fostering behaviours are more commonly observed, compared to otariids. In elephant seals, separation between mothers and pups, and adoptions, are common in the densely packed colonies, especially 
when the pups are quite young. Most of the fostering behaviour is done by females adopting or caring for a pup after losing their own, although simultaneous nursing has also been observed (Riedman and Le Boeuf 1982). Simultaneous allo-suckling is common in grey seals, although the frequency varies among colonies (Perry et al. 1998; McCulloch et al. 1999). Harbour seals at Sable Island fostered only after they had lost contact with their biological pups (Boness et al. 1992; Schaeff et al. 1999). Monk seals display high rates of fostering and milk stealing both in Hawaii (87\% of 30 females in Hawaiian monk seals, with 5-90\% of the lactation spent fostering; Boness 1990) and in the Mediterranean (26.6\% of suckling events involved non-filial pups; Aguilar et al. 2007). In Hawaiian monk seals, most females displayed sequential fostering, by nursing their pups first, and fostering occurring $12.5 \pm 8.93$ days post-partum; fostering was less likely to begin in late lactation (Boness 1990). In Mediterranean monk seals, Aguilar et al. (2007) report both the sequential nursing of pups and simultaneous nursing.

In this study, the probability of allo-suckling increased with Julian day and the longer a mother and a pup had not been seen together (i.e. longer separation time). Most allosuckling events occurred 14-24 days post-partum, a high proportion of which occurred beyond the mother-pup association time (51\% for females and $63 \%$ for pups). Early in the pupping season, fewer females have pupped and are lactating, and so the opportunities for allo-suckling are likely to be fewer. Also early in the season, the average age of pups is younger. Younger pups are more closely associated with their mothers (compared to older pups) and can join them in the water (e.g. from 0 to 3 days post-partum; Bowen et al., 1999), which makes them less likely to be separated for long periods from the mother. However, some pups were also seen allo-suckling in the days following their birth, a small proportion of which were assumed abandoned and not managing to acquire enough resources given their physical appearance which suggested having a very thin blubber layer. Female harbour seals restrict the distance they range from haulouts during the pupping season but will undergo foraging trips before the pups are weaned (Thompson et al. 1994), and as lactation progresses, the extent of their trips increases (Boness et al. 1994). Information on whether the pups accompany their mother to sea during those foraging trips is limited, however. On Sable Island, initial studies suggested females left pups on sandbanks while foraging but later studies showed pups accompanying mothers during lactation (Bowen et al. 1999). Older pups were also seen moving between sites while mothers were absent (Boness et al. 1992). In this study, pups were observed alone during lactation, and modelling results indicated a higher probability of allo-suckling with longer separation time from the mother. Interestingly, photo-ID data in this study showed that allo-suckling also occurred even when the biological mother of a non-filial pup or the female's own pup (or both) were present at the haulout site at the same time (on occasions within a few metres apart). Unfortunately, it was not possible to discern whether the mother and the pup of a pair were aware of their close proximity, and if that influenced their allo-suckling behaviour.

In general, females pupping earlier in the season had longer lactation durations compared to those pupping later in the season, in accordance with photo-ID studies in Loch Fleet (Cordes and Thompson 2013). Overall observed mean lactation duration was $19.6 \pm 8.4$ days and $18.7 \pm 8.0$ days for mother-pup pairs never seen allo-suckling. Both of these are at the lower range of mean lactation durations reported for harbour seals at Loch Fleet (18.6 to 23.4 days, Cordes and Thompson 2013) and Sable Island (24.1 \pm SE 0.44 days, Muelbert and Bowen 1993; 17 to 29 days, Bowen et al. 2001). Modelling results provided no evidence that allo-suckling influenced the duration of the nursing period in pups (18.9 \pm 8.0 days on average) but did show differences in females' lactation duration depending on the allosuckling occurrence within the pair. Females in pairs where both the mother and the pup allo-suckled were estimated to have a lactation duration 1.7 times longer than females in pairs where only the pup allo-suckled and 1.4 times longer than females in pairs in which neither the mother nor the pup allo-suckled, while there was no statistically significant difference with females in pairs where only the mother allosuckled. However, contextualising this in terms of energetic investment by females and energetic gain by pups is complex. Harbour seal mother-pup pairs are not available for observation at every low tide as they spend a high proportion of time in the water from birth and move between haulout sites or between different parts of a haulout site with the tide (Bekkby and Bjørge 2003; Burns 2009). Observations were also missed given the sampling design, which was focused on collecting photo-ID data rather than collecting focal follow behavioural data on targeted lactating females. Consequently, we could not acquire detailed information on the number and duration of suckling vs allo-suckling bouts by females and pups or changes in these throughout the pupping season (e.g. Aguilar et al. 2007). More generally, observations on suckling and allo-suckling events do not provide information on milk intake by the pups, which could then be used as a proxy for maternal investment. Even in studies where suckling time data are available, evidence of its direct relationship with milk intake is weak (Cameron 1998; Childerhouse and Gales 2001).

The costs and benefits of allo-suckling and fostering remain generally poorly understood (Roulin 2002). MacLeod and Lukas (2014) suggest that differences in the relative frequency of allo-suckling in different taxonomic groups might reflect variation in the costs and that the behaviour might quickly evolve when costs of nursing non-filial offspring are 
low. In New Zealand sea lions, multiple nursers (i.e. mothers simultaneously nursing $>1$ pup) spent $50 \%$ more time nursing than single nursers, but the impact of this on females and pups are unknown (Childerhouse and Gales 2001). In South American fur seals, it has been suggested that allo-suckling occurring during early lactation, when pups are small, might not represent a significant investment by females involved in simultaneous nursing but might benefit the colony by increasing the chances of pup survival (Franco-Trecu et al. 2010). If allo-suckling occurs primarily after a mother-pup pair have separated (i.e. the pup is weaned, lost, or dead), the costs of allo-suckling for females are likely to be much reduced as there will be little competition for resources during that season for their own offspring and might thus have little impact on their future reproductive success (Schaeff et al. 1999). In Hawaiian monk seals, for example, lactation duration was the same regardless of whether females sequentially fostered pups during lactation or not (Boness 1990). For the pups, on the other hand, allo-suckling after separating from their biological mothers might simply indicate a strategy for obtaining additional resources post weaning, although the evidence of its impact on their survival is limited. In the Hawaiian monk seal study, Boness (1990) found no differences in size at weaning or on first-year survival between fostered and non-fostered pups. In Antarctic fur seals, higher rates of allo-suckling and of milk stealing have been linked to nutritional stress in pups, with allo-suckling observed more frequently in years when females increased the length of time spent foraging at sea and thus away from their pups (Lunn 1992). A particular case of asynchronous shared nursing in Antarctic fur seals resulted in a noticeably heavier pup compared to other pups from the same cohort (Acevedo et al. 2016). In our study, it was not possible to investigate females' investment in non-filial pups compared to their own pups, in terms of transferred resources through lactation. There were no data available on size at weaning or on pup survival, but a subset of the pups $(n=12), 50 \%$ of which allo-suckled, were photographed and identified in subsequent years as 1-, 2- and 3-year-olds.

In conclusion, findings from this study show that allosuckling is common among harbour seals in the selected study sites in Orkney, and at rates higher than those observed in other populations of harbour seals. We found individual variation in allo-suckling occurrence among females within and between years, with those females allo-suckling other pups having longer lactation durations. Given the elevated energetic costs of lactation (Lee 1996), it remains puzzling why fostering and allo-suckling commonly occur in pinnipeds, and especially in phocids. However, these behaviours might not be strongly selected against if the costs are not high enough to significantly affect females' survival and future reproductive success (Schaeff et al. 1999). Conversely, it might benefit pups by providing extra food in late lactation, when mothers spend more time foraging at sea, and after weaning. However, fostering and allo-suckling behaviours warrant further investigation, as the costs and benefits, and drivers behind these behaviours remain poorly understood and might vary between species and colonies.

Acknowledgments The authors would like to thank Rebecca Hewitt, Isla Graham and Paul Thompson at the University of Aberdeen Lighthouse Field Station for sharing their extensive knowledge on harbour seal photo-ID studies and behaviour, and to Georgia Palmer for her help collecting data in 2017. We are grateful to landowners and neighbours from Burray and South Ronaldsay (Orkney) for their interest in the project. We would also like to thank two anonymous reviewers and the associate editor for their insightful comments on an earlier version of the manuscript. This study was made possible through funding from the Scottish Government (grant number MMSS/002/15).

Author contribution The study was conceived and designed by MAC. Data were collected and processed by MAC, IL and EH. Data analysis was conducted by MAC and LSH. All authors contributed to writing and approving the final manuscript.

Funding This study was funded by Scottish Government (grant number MMSS/002/15).

Data availability The research data underpinning this publication can be accessed at https://doi.org/10.17630/07c2d13f-3f4e-4f4b-adb0c20ae0ab6f6b (Arso Civil et al. 2021).

Code availability Not applicable.

\section{Declarations}

Ethics approval This research was approved by the University of St Andrews Animal Welfare and Ethics Committee (AWEC). The collection of photo-identification data and associated observational data followed institutional guidelines and did not require U.K. Home Office licencing.

Consent to participate Not applicable.

Consent for publication Not applicable.

Conflicts of interest The authors declare no competing interests.

Open Access This article is licensed under a Creative Commons Attribution 4.0 International License, which permits use, sharing, adaptation, distribution and reproduction in any medium or format, as long as you give appropriate credit to the original author(s) and the source, provide a link to the Creative Commons licence, and indicate if changes were made. The images or other third party material in this article are included in the article's Creative Commons licence, unless indicated otherwise in a credit line to the material. If material is not included in the article's Creative Commons licence and your intended use is not permitted by statutory regulation or exceeds the permitted use, you will need to obtain permission directly from the copyright holder. To view a copy of this licence, visit http://creativecommons.org/licenses/by/4.0/. 


\section{References}

Acevedo J, Torres D, Aguayo-Lobo A (2016) Offspring kidnapping with subsequent shared nursing in Antarctic fur seals. Polar Biol 39:1225-1232

Aguilar A, Cappozzo LH, Gazo M, Pastor T, Forcada J, Grau E (2007) Lactation and mother-pup behaviour in the Mediterranean monk seal Monachus monachus: an unusual pattern for a phocid. J Mar Biol Assoc UK 87:93-99

Allen DM (1971) Mean square error of prediction as a criterion for selecting variables. Technometrics 13:469-475

Arso Civil M, Hague E, Langley I, Scott-Hayward L (2021) Allo-suckling occurrence and its effect on lactation and nursing duration in harbour seals (Phoca vitulina) in Orkney, Scotland (datasets). In: University of St Andrews Research Portal, https://doi.org/10. 17630/07c2d13f-3f4e-4f4b-adb0-c20ae0ab6f6b

Arso Civil M, Smout S, Duck C et al (2018) Harbour seal decline vital rates and drivers. Report to Scottish Government HSD2. Sea Mammal Research Unit, University of St Andrews

Arso Civil M, Smout S, Onoufriou, et al (2016) Harbour seal decline - vital rates and drivers. University of St Andrews, Sea Mammal Research Unit

Barton K (2019) MuMIn: multi-model inference. R package version 1.43.15, https://CRAN.R-project.org/package=MuMIn

Bekkby T, Bjørge A (2003) Joint diving behaviour of harbour seal (Phoca vitulina) females and pups in the lactation period. Sarsia 88:369-372

Belsley D, Kuh E, Welsch R (1980) Regression diagnostics: identifying influential data and sources of collinearity. John Wiley \& Sons, New York

Bolger DT, Morrison TA, Vance B, Lee D, Farid H (2012) A computer-assisted system for photographic mark-recapture analysis. Method Ecol Evol 3:813-822

Boness DJ (1990) Fostering behavior in Hawaiian monk seals: is there a reproductive cost? Behav Ecol Sociobiol 27:113-122

Boness DJ, Bowen D, Iverson SJ, Oftedal OT (1992) Influence of storms and maternal size on mother-pup separations and fostering in the harbor seal, Phoca vitulina. Can J Zool 70:1640-1644

Boness DJ, Bowen WD, Oftedal OT (1994) Evidence of a maternal foraging cycle resembling that of otariid seals in a small phocid, the harbor seal. Behav Ecol Sociobiol 34:95-104

Boness DJ, Craig MP, Honigman L, Austin S (1998) Fostering behavior and the effect of female density in Hawaiian monk seals, Monachus schauinslandi. J Mammal 79:1060-1069

Boulva J, McLaren IA (1979) Biology of the harbor seal, Phoca vitulina, in eastern Canada. Dept. of Fisheries and Oceans, Ottawa

Bowen W, Iverson SJ, Boness DJ, Oftedal OT (2001) Foraging effort, food intake and lactation performance depend on maternal mass in a small phocid seal. Funct Ecol 15:325-334

Bowen W, Iverson SJ, McMillan J, Boness D (2006) Reproductive performance in grey seals: age-related improvement and senescence in a capital breeder. J Anim Ecol 75:1340-1351

Bowen WD (1991) Behavioural ecology of pinniped neonates. In: Renouf D (ed) The Behaviour of Pinnipeds. Springer, Netherlands, Dordrecht, pp 66-127

Bowen WD, Beck C, Austin D (2009) Pinniped ecology. In: Perrin WE, Würsig B, Thewissen JGM (eds) Encyclopedia of marine mammals. Elsevier, San Diego, pp 852-861

Bowen WD, Boness DJ, Iverson SJ (1999) Diving behaviour of lactating harbour seals and their pups during maternal foraging trips. Can J Zool 77:978-988

Bowen WD, Oftedal OT, Boness DJ (1992) Mass and energy transfer during lactation in a small phocid, the harbor seal (Phoca vitulina). Physiol Zool 65:844-866
Burnham KP, Anderson DR (2002) Model selection and inference: a practical information theoretic approach, 2nd edn. Springer, New York

Burns JJ (2009) harbor seal and spotted seal: Phoca vitulina and $P$. largha. In: Perrin WF, Würsig B, Thewissen JGM (eds) Encyclopedia of Marine Mammals, 2nd edn. Academic Press, London, pp 533-542

Cameron EZ (1998) Is suckling behaviour a useful predictor of milk intake? A review. Anim Behav 56:521-532

Childerhouse S, Gales N (2001) Fostering behaviour in New Zealand sea lions Phocarctos hookeri. New Zeal J Zool 28:189-195

Clutton-Brock TH, Albon SD, Guinness FE (1989) Fitness costs of gestation and lactation in wild mammals. Nature 337:260-262

Cordes L, Thompson P (2013) Variation in breeding phenology provides insights into drivers of long-term population change in harbour seals. Proc R Soc B 280:20130847

Cottrell PE, Jeffries S, Beck B, Ross PS (2002) Growth and development in free-ranging harbor seal (Phoca vitulina) pups from southern British Columbia, Canada. Mar Mammal Sci 18:721-733

Cunningham L (2009) Using computer-assisted photo-identification and capture-recapture techniques to monitor the conservation status of harbour seals (Phoca vitulina). Aquat Mamm 35:319-329

Desprez M, Gimenez O, McMahon CR, Hindell MA, Harcourt RG (2018) Optimizing lifetime reproductive output: intermittent breeding as a tactic for females in a long-lived, multiparous mammal. J Anim Ecol 87:199-211

Fox J, Weisberg S (2019) An $\{\mathrm{R}\}$ Companion to applied regression, 3rd edn. Sage, Thousand Oaks, CA, https://socialsciences.mcmas ter.ca/jfox/Books/Companion/

Franco-Trecu V, Tassino B, Soutullo A (2010) Allo-suckling in the South American fur seal (Arctocephalus australis) in Isla de Lobos, Uruguay: cost or benefit of living in a group? Ethol Ecol Evol 22:143-150

Gemmell NJ (2003) Kin selection may influence fostering behaviour in Antarctic fur seals (Arctocephalus gazella). Proc R Soc Lond B 270:2033-2037

Hall AJ, Mackey B, Kershaw JL, Thompson P (2019) Age-length relationships in UK harbour seals during a period of population decline. Aquat Conserv 29:61-70

Hastings KK, Hiby LA, Small RJ (2008) Evaluation of a computerassisted photograph-matching system to monitor naturally marked harbor seals at Tugidak Island, Alaska. J Mammal 89:1201-1211

Hoffman JI, Amos W (2005) Does kin selection influence fostering behaviour in Antarctic fur seals (Arctocephalus gazella)? Proc R Soc Lond B 272:2017-2022

Insley S, Phillips AV, Charrier I (2003) A review of social recognition in pinnipeds. Aquat Mamm 29:181-201

Iverson SJ, Bowen WD, Boness DJ, Oftedal OT (1993) The effect of maternal size and milk energy output on pup growth in grey seals (Halichoerus grypus). Physiol Zool 66:61-88

Lang SLC, Iverson SJ, Bowen WD (2005) Individual variation in milk composition over lactation in harbour seals (Phoca vitulina) and the potential consequences of intermittent attendance. Can J Zool $83: 1525-1531$

Lee PC (1996) The meanings of weaning: growth, lactation, and life history. Evol Anthropol 5:87-98

Lunn NJ (1992) Fostering behaviour and milk stealing in Antarctic fur seals. Can J Zool 70:837-839

MacLeod KJ, Lukas D (2014) Revisiting non-offspring nursing: allonursing evolves when the costs are low. Biol Lett 10:20140378

Maniscalco JM, Harris KR, Atkinson S, Parker P (2007) Alloparenting in Steller sea lions (Eumetopias jubatus): correlations with misdirected care and other observations. J Ethol 25:125-131 
McCulloch S, Pomeroy PP, Slater PJ (1999) Individually distinctive pup vocalizations fail to prevent allo-suckling in grey seals. Can J Zool 77:716-723

Muelbert MMC, Bowen WD (1993) Duration of lactation and postweaning changes in mass and body composition of harbour seal, Phoca vitulina, pups. Can J Zool 71:1405-1414

Oftedal OT, Boness DJ, Tedman RA (1987) The behavior, physiology, and anatomy of lactation in the pinnipedia. Curr Mammal $1: 175-245$

Packer C, Lewis S, Pusey A (1992) A comparative analysis of nonoffspring nursing. Anim Behav 43:265-281

Perry EA, Boness DJ, Fleischer RC (1998) DNA fingerprinting evidence of nonfilial nursing in grey seals. Mol Ecol 7:81-85

Pitcher BJ, Ahonen H, Charrier I, Harcourt RG (2011) Allosuckling behavior in the Australian sea lion (Neophoca cinerea): an updated understanding. Mar Mammal Sci 27:881-888

R Core Team (2019) R: A language and environment for statistical computing. R Foundation for Statistical Computing. R Foundation for Statistical Computing, Vienna, Austria,https://www.R-proje ct.org/

Reder S, Lydersen C, Arnold W, Kovacs KM (2003) Haulout behaviour of high arctic harbour seals (Phoca vitulina vitulina) in Svalbard, Norway. Polar Biol 27:6-16

Renouf D (1984) The vocalization of the harbour seal pup (Phoca vitulina) and its role in the maintenance of contact with the mother. J Zool 202:583-590

Riedman ML (1982) The evolution of alloparental care and adoption in mammals and birds. Q Rev Biol 57:405-435

Riedman ML, Le Boeuf BJ (1982) Mother-pup separation and adoption in northern elephant seals. Behav Ecol Sociobiol 11:203-215

Roulin A (2002) Why do lactating females nurse alien offspring? A review of hypotheses and empirical evidence. Anim Behav 63:201-208

Rubertus RP (1983) Observations on a colony of common seals (Phoca vitulina) on Burray (Orkney) in July 1982. Final report to the European Communities (projectnumber ENV616N) ,RIN, Arnhem, The Netherlands.
Sauvé CC, Beauplet G, Hammill MO, Charrier I (2015) Motherpup vocal recognition in harbour seals: influence of maternal behaviour, pup voice and habitat sound properties. Anim Behav 105:109-120

Schaeff C, Boness D, Bowen W (1999) Female distribution, genetic relatedness, and fostering behaviour in harbour seals, Phoca vitulina. Anim Behav 57:427-434

Schulz TM, Bowen WD (2004) Pinniped lactation strategies: evaluation of data on maternal and offspring life history traits. Mar Mammal Sci 20:86-114

Scott-Hayward L, Oedekoven CS, MacKenzie M, Walker CG (2018) Guide for the MRSea package: statistical modelling of bird and cetacean distributions in offshore renewables development areas. University of St, Andrews contract for Marine Scotland, St. Andrews, Fife, Scotland, UK

Smiseth PT, Lorentsen S-H (2001) Begging and parent-offspring conflict in grey seals. Anim Behav 62:273-279

Thompson D, Duck C, Morris C, Russell DJF (2019) The status of harbour seals (Phoca vitulina) in the UK. Aquat Conserv 29:40-60

Thompson PM, Miller D, Cooper R, Hammond PS (1994) Changes in the distribution and activity of female harbour seals during the breeding season: implications for their lactation strategy and mating patterns. J Anim Ecol 63:24-30

Walker CG, Mackenzie ML, Donovan CR, O’Sullivan MJ (2011) SALSA - a spatially adaptive local smoothing algorithm. J Stat Comput Sim 81:179-191

Wilson SC, Jones KA (2018) Behaviour of harbour seal (Phoca vitulina vitulina) mother-pup pairs in Irish Sea intertidal habitats. Biol Environ 118B:13-27

Publisher's note Springer Nature remains neutral with regard to jurisdictional claims in published maps and institutional affiliations. 